\title{
Developing ICT Services in a Low-Resource Development Context
}

\author{
Anna Bon ${ }^{\star}$, Hans Akkermans ${ }^{\star}$ and Jaap Gordijn ${ }^{\star}$ \\ The Network Institute, Vrije Universiteit Amsterdam, \\ De Boelelaan 1081, 1081 HV Amsterdam, The Netherlands \\ a.bon@vu.nl (orcid.org/0000-0001-7504-7274), hans.akkermans@akmc.nl, \\ j.gordijnevu.nl (orcid.org/0000-0002-6401-3850)
}

\begin{abstract}
Despite an urgent need for social and technological innovation to improve wellbeing of people and communities in poor regions of the world, information and communications technology (ICT) service delivery has not yet been very successful in regions with low levels of literacy, poor infrastructures, and limited purchasing power. High rates of failure, reported in various studies, point at a frequent mismatch between deployed technologies and local needs and contexts. Still, no practical field-validated methodologies for ICT service innovation in low-resource development contexts have been proposed that offer adequate ways to meet local needs and contexts and assess sustainability before deployment. This article outlines a framework for development of ICT services in low-resource development contexts, covering the full lifecycle of ICT service innovation. This framework is based on extensive field research, and shows how a collaborative, adaptive, and iterative methodology can address a set of key sociotechnical concerns and issues widely encountered in developing and emerging countries.
\end{abstract}

Keywords: ICT4D, services, context, needs assessment, sustainability.

\section{Introduction}

Technological innovation and information and communications technologies (ICTs) are considered key enablers for social and economic development, even in technologically less advanced regions of the world ${ }^{1}$. Various studies have demonstrated a relationship between access to information facilitated by ICT and improved well-being of people and communities in developing countries (e.g. [1], [2], [3]). However, essential differences exist regarding the contexts in which the proclaimed potential of ICT services and solutions is to be realized. Most of the literature is concerned with the Global North, where the availability of advanced technologies, skills, and resources is commonly taken for granted. In contrast, in the Global South one has to deal with

\footnotetext{
${ }^{1}$ See the United Nations (UN) Sustainable Development Goals 2015-2030,

https://sustainabledevelopment.un.org.

${ }^{\star}$ Corresponding author
}

(C) 2016 Bon et al. This is an open access article licensed under the Creative Commons Attribution License (http://creativecommons.org/licenses/by/4.0).

Reference: A. Bon, H. Akkermans and J. Gordijn, "Developing ICT Services in a Low-Resource Development Context," Complex Systems Informatics and Modeling Quarterly, CSIMQ, no. 9, pp. 84-109, 2016. [Online]. Available: https://doi.org/10.7250/csimq.2016-9.05 
fundamentally different situations that we in this article will refer to as low-resource development contexts. This warrants special study of such low-resource contexts in ways that are critical of the validity and adoption of Global North type assumptions. This is what the present article sets out to do.

In Africa, the use of ICTs is still limited, especially in rural regions, where infrastructure is poorly developed (e.g. no electricity grids, no internet connections), levels of literacy are low $^{2}$, and economic conditions are demanding ${ }^{3}$. Despite many limitations, there has been a quick expansion of mobile telephony over the whole continent of Africa in recent years ${ }^{4}$. In 2014, 69 out of 100 people in Africa had a cellular subscription, whereas in 2002 this was only 4 out of 100 inhabitants ${ }^{5}$. Recent success of mobile banking e-services in e.g. Kenya has shown that innovative ICT services can be rapidly diffused, even in poor environments [4].

In wealthier parts of the world, commercial ICT services are commonly internet-based such as NetFlix, Spotify, Facebook, and Twitter. However, internet is not available in large parts of (rural) Africa, where the mobile 2G (GSM) network is the only digital infrastructure available, and an upgrade to $3 \mathrm{G}$ or $4 \mathrm{G}$ networks (which allow internet access) is not expected in the near future, due to high investments and low revenues for mobile operators ${ }^{6}$. Given the technical and economic limitations and cultural issues, a roll-out of conventional, internet-based, and text-based ICT services will simply not work for poor rural areas in Africa. Creative solutions are needed to bootstrap ICT service innovation and to serve poor people in rural regions.

Currently, ICT deployments in developing regions are often funded by donors such as the World Bank, the United Nations or large private philanthropic organizations such as the Bill \& Melinda Gates Foundation, through so-called ICT for Development (ICT4D) projects. Despite many investments and efforts, high rates of failure are reported for ICT4D deployments [5]. There seems to be a frequent mismatch between deployed technologies and local goals, needs, and contexts, resulting in unsustainable solutions (see e.g. [6], [7], [8]).

One example of a large-scale project that did not match the needs of the rural population is the launch, funded by the national government of Rwanda, of thirty community telecenters aimed at promoting socio-economic development in rural regions [9]. Telecentres are physical service centers, typically equipped with personal computers [10], offering mainstream ICT facilities such as email, web browsing, office applications, and printing. In rural Rwanda, where $70-90 \%$ of the rural population only speak the local language Kinyarwanda, while literacy levels of the adult population are around 50\% [11], the mainstream text-based applications offered in the telecentres do not reach the people they intend to serve, as shown by a recent field study [9].

Another example of failure due to contextual mismatch is reported for a three-year project in Tanzania, the Maji Matone project, aimed at improving access to clean water for rural communities. During this project, people from the communities were requested to send feedback on the local state of drinking water using SMS-text messages. These data were to be used to inform the local government of Tanzania ${ }^{7}$. Although it was expected that 3,000 SMS messages would be received from the community members, only 53 were received. The reason was that the project designers had not taken into account the poor mobile coverage in the region. Apart from that, water collection turned out to be a task of women and children, who did not own a mobile phone, and so could not report the requested information to the project data store ${ }^{8}$. A proper analysis before, or

\footnotetext{
${ }^{2}$ E.g. in rural Mali, adult literacy is less than 35 percent.

3 The average income in Mali is less than $2 \$$ a day.

${ }^{4}$ Source: http://www.itu.int/en/ITU-D/Statistics/Pages/default.aspx.

5 Source: http://www.itu.int.

6 Source: GSMA: The Mobile Economy Sub-Saharan Africa 2015.

${ }^{7}$ Source: http://www.daraja.org/our-work/rtwp.

8 Source: http://vulnerabilityandpoverty.blogspot.nl/2012/12/by-inka-barnett-use-of-information-and.html.
} 
even during, the project would have revealed the contextual issues, and a flexible approach might have led to adjustment and adaptation of the initial project plans.

The scientific literature on ICT for Development also expresses concern about the high rate of failure of ICT4D projects. This literature can be roughly divided into three categories: (i) social-science, often ethnographic, field studies that analyse the effects and impact of ICTs on people in developing regions (e.g. [2], [3], [12]); (ii) technical studies that describe developed local or regional ICT deployments or present technical tools (e.g. [13], [14], [15], [16], [17]); (iii) desk research studies that consider various policy aspects at a high conceptual level (e.g. [18], [19], [20]). User-centered field studies in ICT for development mainly originate from the field of human-computer interaction (HCI) for development [21], [22], [23], [24], [25]. These studies focus on contextualization of user interfaces to local culture and on usability of systems for end-users, but do not cover the complete lifecycle of ICT service development, from user-centered needs assessment and context analysis, to design, deployment, evaluation, ex ante business modeling and sustainability assessment. As a remedy against ICT4D project failure, rigorous monitoring and evaluation is typically proposed to improve outcomes (e.g. [1], [6]). The problem with such methodological solutions is that they strongly tend to focus on emerged issues and problems after the fact. Despite an overall large body of scientific literature on ICT4D (948 papers between 2000 and 2010 [26]), not many studies present field-validated methodology that is able to address the issue of success and sustainability of ICT4D deployments ex ante. This is the central topic of the present article.

In this article we propose a framework to develop ICT-enabled services for people in low-resource environments such as rural Africa, that covers the full lifecycle. The framework consists of five configurable components: (i) needs assessment with local users and stakeholders; (ii) context analysis to really understand the constrained environment; (iii) use case modeling and requirements elicitation; (iv) business modeling and sustainability assessment; (v) multiple cycles of implementation and deployment, so as to find out whether the proposed services really work in the target environment and are of value to users and other stakeholders.

Our ICT4D framework results from extensive sociotechnical field action research carried out in West Africa (Ghana, Burkina Faso, Mali) in the period 2009-2016. As there are many unknowns at the start of any ICT4D research and development program, a flexible, open and reflective research strategy and methodology is called for (see e.g. [27], [28]), aimed at achieving an in-depth understanding of the real-world problems while designing ICT4D services in their (initially for the researchers unfamiliar) proper local context [29]. Thus, research methodology has a strong learning-by-doing element plus action-research reflection on top, borrowing aspects from technology innovation methodologies such as Living Labs [30], [31], Agile Development Methods [32], [33] and user-centered use case analysis and requirements engineering [34]. More generally, partnering and collaboration with local stakeholders is essential throughout ICT4D research (cf. also [28]).

This article is structured as follows. In Section 2 we present the major concerns and issues that any ICT4D framework should be able to address, and we outline the main components of such a framework. Next, each component of the framework is explained and exemplified with experiences in developing ICT services in rural Africa in Sections 3-7. Finally, Section 8 considers our framework as an integrated whole, discusses its process and research strategy aspects, positions our framework within the wider scientific debate concerning development and technology, and summarizes the main conclusions.

\section{A Framework to Develop ICT4D Services}

An ICT4D development framework should be able to address a set of specific concerns, in addition to and beyond the usual ones that hold for ICT development approaches in general. Namely, the 
situatedness of ICT systems and system developments requires the capability to cater for situations specific to developing regions and emerging countries.

ICT4D framework concerns. Below, we list and explain these concerns $(\mathrm{C} i)$ in some more detail. They derive from and are a systematized formulation of our own extensive field experience in ICT4D projects. In addition, there is a vast study literature of technical reports from non-governmental organizations (NGOs), specialized research institutes, United Nations, World Bank, etc., only some of which can be cited in this article, that further substantiates the issues at hand.

C 1 Local needs unknown. A common experience is that service needs of inhabitants of the 'Global South' are very different from customer needs in Western societies. E.g. a reliable weather service, although seen as trivial in the West, would be of great added value to rural communities in the African drylands as it simply does not exist now in any usable and accessible form. Thus, an ICT4D project should explicitly focus on the real needs of the prospective beneficiaries or end-users, with an eye on selecting a portfolio of ICT services that really matter to those users. Although quite often conflated in ICT systems development, we note that needs and requirements are to be considered and distinguished as different concepts. Needs are states of felt deprivation of some basic satisfaction [35] and, therefore, have a customer value connotation (note that this is independent of any system or technology under consideration), whereas requirements describe functional behaviour or quality demands related to the (prospective) information system at hand.

C 2 Context unknown. The ICT4D development framework has to deal with situations where the context of the ICT service is largely unknown. In most cases, the service itself is not really understood by the developers before the project starts, in contrast to many service development projects in Western societies. Therefore, ICT service developers should take considerable time to become familiar with the constrained environment of the service end-users. In many cases, (part of) the ICT developers have a Western societal orientation, and are insufficiently familiar with the circumstances of the end-users, as well as the limitations of the environment in which they live.

C 3 Significant levels of low literacy. Various levels of low-literacy are widespread, and this has a severe impact on service design. It restricts the affordances of much available technology (e.g. SMS is out of the question), and even is a showstopper for certain types and channels of services. One of the ways to deal with this is to explicitly take into account the preferred mode of interaction of users with the service, e.g. via voice.

C 4 Availability of crucial technology and infrastructure. An important constraint in ICT4D projects is the problematic availability of important infrastructures and technologies. In rural regions an electricity network is commonly not present, while in urban areas power outages are a regular phenomenon. As a consequence, internet connection is absent in rural regions, and suffers from high cost and less-than-desirable quality (e.g. needed bandwidth) and reliability in the urban areas. Communication technology, in particular mobile telephony (still mostly feature phones, not smartphones), is widely available, but expensive; in rural regions radio is a popular mass communication medium (more than $\mathrm{TV}$, because of its electricity demands). Also, hosting of ICT services is not always possible or at least is very costly. Therefore, during the design process, the developers should keep in mind that service deployment already in the purely technical sense is a real down-to-earth problem, and innovative solutions should be sought.

C 5 Low purchasing power of end users. In developing countries, purchasing power of the intended end-users is relatively low. Therefore, many services, even if technically feasible, may not be financially feasible, simply due to customer cost considerations. Hence, an ICT4D 
framework should support the evaluation of the prospective service, specifically, with respect to the purchasing power of end-users.

C 6 Lacking understanding of ICT possibilities. For many intended end-users, it is the first time that they are exposed to ICT technologies such as Internet and Web. This complicates the ICT requirements elicitation process, and before that, finding an adequate ICT-enabled service in the first place. Therefore, the ICT4D framework should deal with ICT-agnostic end-users, for instance by demonstrating successful ICT services in a recognizable development context, showing rapid prototypes and mock-ups, etc.

C 7 Mismatch between donor-sponsor goals and 'beneficiary' end-user goals. In practice, many ICT4D projects receive donor funding (e.g. from the EU, World Bank, large philanthropic funds such as the Gates Foundation) to increase access to and use of ICT in developing countries. Funding agencies often do not have a clear idea about the end-user services to be developed. More generally, there is no convincing reason to upfront assume that donor agency goals will match with those of the supposed beneficiaries living in another part of the world. Goals of donor agencies are typically more high-level and generic. The goals of end-users, in contrast, are mostly much more specific: farmers want to have a reliable weather forecast, people want to announce messages to an audience without having to travel for doing so, etc. The concern here is how to satisfy the generic goals of the funding agency, while at the same time developing services that are perceived as relevant and valuable by local end-users.

C 8 Sustainability concerns. As explained above, ICT4D projects often receive donor funding. Such funding is essential to develop and initiate the service. However, many ICT4D services discontinue once donor funding disappears. In such cases, the service is not sustainable. During ICT4D service development, a clear understanding should be created concerning financial sustainability. Typical questions that emerge are: "What is the delivery and maintenance structure of the service after the piloting phase?", "Can the service survive in the longer run by end-user fees or other ways of cost recovering?", etc.

A framework for ICT4D service development. To cater for these concerns, we propose a framework that consists of five components or aspects: (i) context analysis, (ii) needs assessment, (iii) use case and requirements analysis, (iv) sustainability assessment, (v) developing, testing, deploying. Because of its iterative nature, we refer to the framework as a configurable list of 'components' rather than as a series of sequential 'phases'. Therefore, in practice the framework components heavily interact with each other, instead of being applied in a traditional waterfall approach (see Section 8 for a more elaborate discussion).

We here briefly summarize the framework according to Figure 1; a detailed discussion is presented in Sections 3-7.

- Context analysis. The local situations in Africa are largely unknown to many ICT4D developers who often have a non-African background. Therefore, sufficient time should be spent on becoming familiar with the context and the associated constraints and demands. Conversely, African stakeholders and prospective end users will need some level of acquaintance with what advanced ICT can(not) possibly bring to them.

- Needs assessment. The ultimate goal is to develop services that are of value to the end users. Therefore, one has to pay explicit attention to the customer (end-user) needs. As pointed out earlier, this is not the same as the well-known requirements for information systems. Needs are states of felt deprivation [35]. A complicating factor is that many people are unaware of the kind of needs that may be satisfied by means of ICT-enabled services. Therefore, e.g. demos of successful ICT services in Africa can be given to help create this awareness.

- Use case and requirements analysis. Once needs are selected for further exploration, use cases (in a specific format, discussed in Section 5) are developed and requirements analysis is done. In order to communicate with the local stakeholders, mockups and prototypes are developed, 
to facilitate requirements elicitation and validation. Usually this also leads to revised, and more precisely articulated end-user needs.

- Developing, testing, deploying. For the selected service, a working prototype is developed, and tested in the field. Evaluation results are used to iteratively and adaptively develop a more mature system.

- Sustainability analysis. Many ICT-enabled services in Africa ultimately fail because of a lack of a business model (how economic value flows through a network of parties). ICT systems imply costs and use of resources, and some party or parties have to cater for this somehow. In ICT4D projects, there is often a donor (e.g. EU, World Bank, etc.) that pays for the initial costs. However, at a certain point in time, this donor funding ends, and then the service has still to be able to continue from a financial perspective. From earlier experiences we know that the business model significantly influences the shape of the service at hand, and often there are different business-model alternatives that warrant consideration. Therefore, already in an early stage, business-model studies for the service are to be carried out, supporting decision making for the continuity of service beyond the pilot and initial stages.

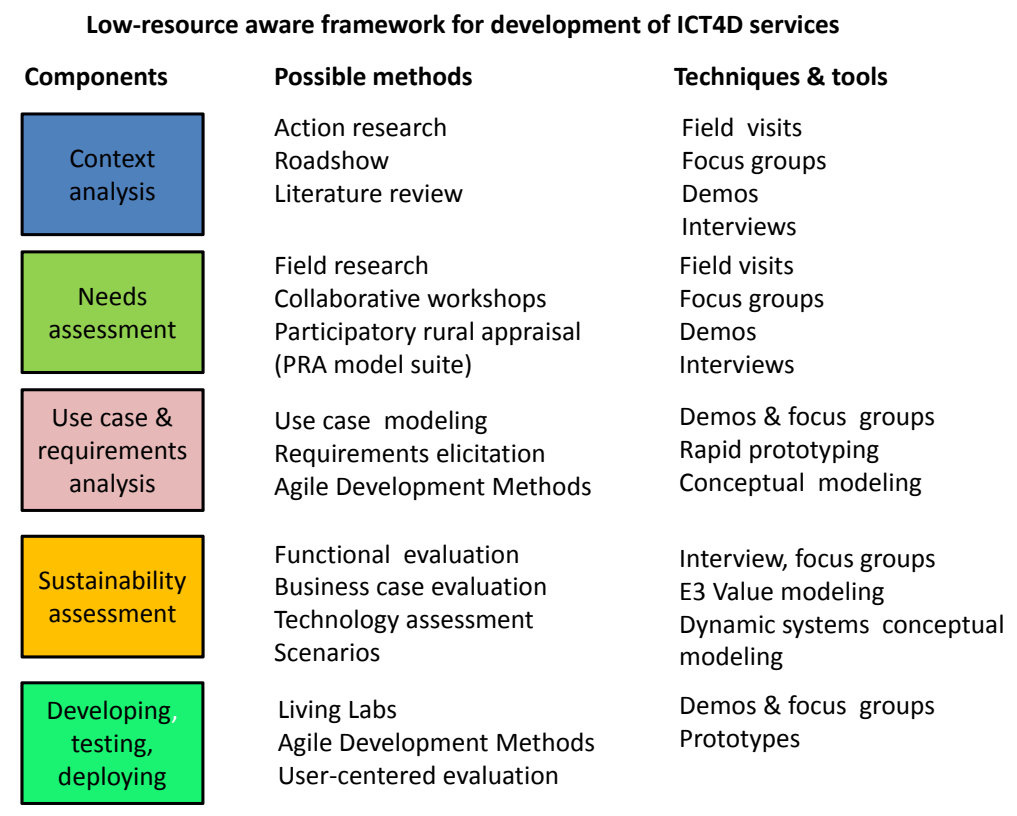

Figure 1. Framework for ICT4D Service Development with five components, with related methods and tools

\section{Context Analysis - Experiencing the Environment}

Our approach to ICT4D is based on the idea that different stakeholders (users, developers) have different world views. Envisaged users may live in rural areas, while developers often are from urban areas, also in western countries. It is essential to bridge cultural distances at the earliest stage. This is done by teaming up, creating partnerships and expressing interest in each other's ideas and expertise.

Context analysis brings new experiences and perspectives. An example: one of our colleague researchers stayed for a month in a rural village in Ghana for a context analysis, and experienced how much time was spent by the villagers every day, just to walk to a distant well to fetch drinking water for the village.

Collaborative workshops, focus group discussions, interviews and group sessions are done in the local environment of the users. A visit to a representative site, and a meeting with the envisaged 
users marks the start of the field research. Workshop sessions are usually chaired by a local person, who is as a partner part of the core team. During workshops and group meetings the ICT developers respect local habits, protocols, and traditions. Partnerships with local organizations are important as an introduction to the local communities. Local partners are translators and provide much information about local culture.

Researchers and developers must take an open attitude, observe and try to obtain as much information as possible from the meetings. Since user involvement is key, the crucial question is: "Are local communities indeed interested in participation in and co-creation of new technologies and services?" Only if yes, one can proceed.

Other questions have to be asked: "How is the technical infrastructure locally?;" "What is the general level of literacy/computer literacy/formal education of local users?;" "What is the purchasing power/how much money are people prepared/able to spend, to get relevant information?;" and about stakeholders: "Who are the stakeholders involved?;" "Who are users and potential service providers?;" "Who would be other beneficiaries?;" "How are the relationships between these stakeholders?;" "What are their roles, strategies, intentions?".

At the end of the context analysis, a core research team is established, which includes researchers, local partners (liaisons who make the connection, e.g. NGOs, local researchers, local content experts, local researchers, local ICT service providers such as local radio stations and local ICT businesses), and several key users. The developers team includes requirements engineer(s), information analyst, project manager, hands-on ICT developers, and local ICT developers or potential service providers (business partners) such as local NGOs or community radio stations.

Case: Context analysis in Ranawa, Burkina Faso. A first context analysis field visit including focus group discussion was done by our team in September 2009 in Ranawa, a rural community of 2300 inhabitants, in the Central Plateau of Burkina Faso. This village is representative for a low-resource, low-tech rural community. People in this rural region live from subsistence farming and produce millet, sorghum, sesame, and have some livestock.

This village was selected for our research, because the farmers in Ranawa are involved in regreening, a grassroots-level farmer- and community-led emergent phenomenon in West Africa, in which local farmers are applying local, inexpensive, low-tech innovations to increase the number of trees on their fields to improve agricultural output. Better distance communication in disseminating these promising innovations could be of value to local communities.

After a visit through the fields, a focus group discussion takes place with the chief and twelve villagers, under a tree (Figure 2). Translations were made simultaneously from the local language Moré to French and vice-versa by our local partner - staff members from a local NGO named Réseau MARP - who introduced us here. Despite the translations, the conversation goes well.

In Ranawa up to $98 \%$ of households use mobile phones for social interaction and business, e.g. to ask for market prices in town, to negotiate with potential customers about prices of commodities. On average 1,000-5,000 CFA francs (2-10 euros) is spent per month on mobile telephony. Some people in the village earn money by selling airtime (telephone units) in very small units. However, there is no electricity in this village. Phones are charged by a person with a motor cycle battery (phone charging is his business).

The Ranawa community states that mobile telephony is essential for life and work. The villagers express themselves to be open to innovation and new systems of communication and access to relevant information. However, there is a lack of infrastructure (electricity, internet), the illiteracy rate is high, especially amongst elderly people and women, and spoken communication is mainly in the local language. We notice an interested attitude towards new technologies. Extra costs are acceptable, but only if the new technologies bring real advantages. All this extensive field work is crucial in providing heavily needed information inputs for a successful ICT4D project. 


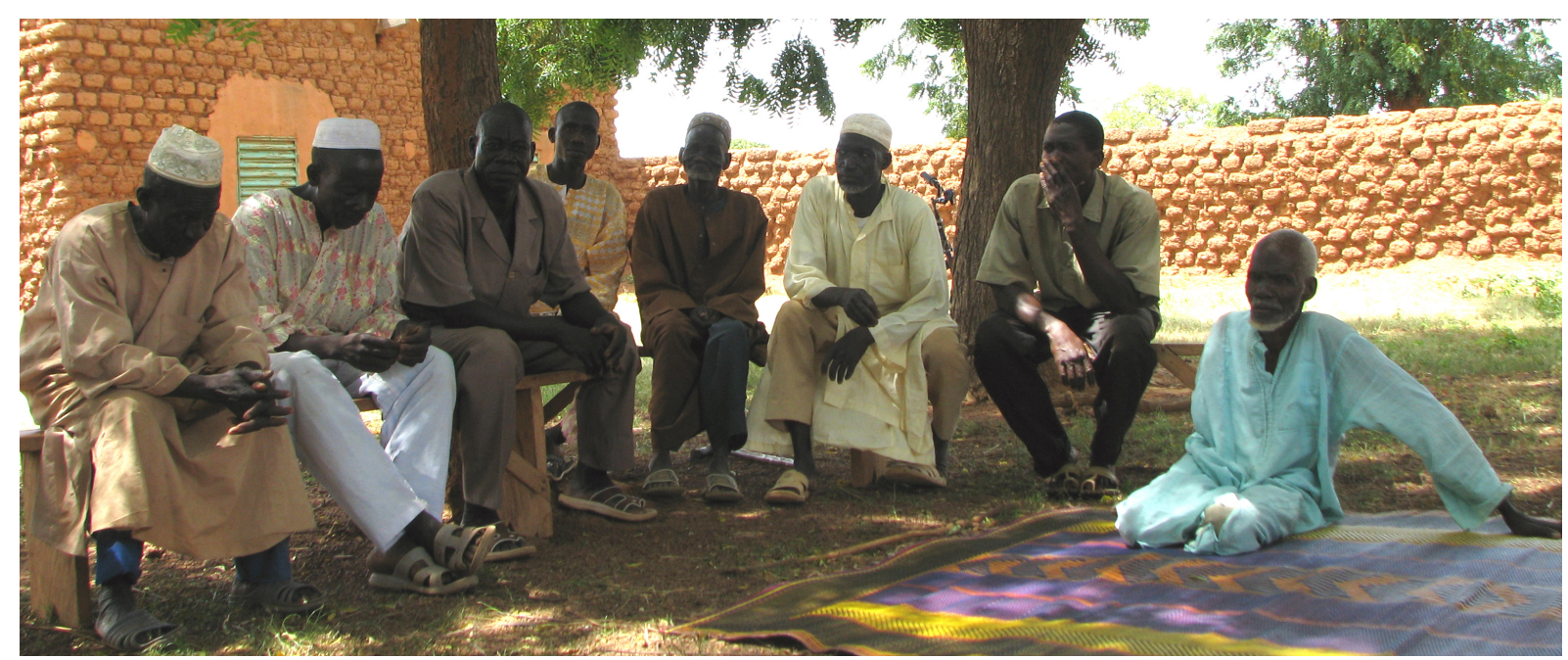

Figure 2. A context analysis visit to the Ranawa village, Burkina Faso, September 2009

\section{Needs Assessment - Eliciting Objectives of Users}

Having established a research team and built partnerships with local communities, it is important to understand what users perceive as a problem. Since, at the start of the project, developers and users often do not know what they do not know, road shows are organized, representative sites are visited and collaborative workshops and focus group discussions are organized. Developers need to understand the users' (operational) goals - as ICTs should serve and improve their lives and work. Since users may be unfamiliar with ICTs, demos are given to encourage brainstorming and creative thinking. During these sessions, technology demos are given, e.g. voice-based market information, a voice-based communication platform, a farmer help-line on mobile phone, in the local language.

Demos are useful to trigger discussions and encourage group brainstorming about existing constraints that might be solved with innovative technologies. Are problems related to lack of information and/or difficulties in communication? For what reason would potential users value a certain (technological) solution? Are there alternatives? To answer this, workshops and focus group discussions are organized with a number of representative key users in their local environment.

The participants group is divided into smaller teams (of 5-6 people) who are asked to make an inventory of domains of concerns and related problems. Sometimes, participants are unable to write, so each group must include a person with literacy skills. When finished with the group work sessions, the results are presented by each group in a plenary session. Key ideas, user stories and business ideas are discussed, grouped, and summarized.

Having identified a number of problems, there are extensive brainstorm sessions for solutions and prioritizing and selecting the most promising ideas. This is based on relevance: which problem is considered to be most pressing by the users? Next, for each of the selected problems a solution space is sought, which can include an optional range of solutions. From the range of possible solutions, a selection is jointly made what to further elaborate.

Selection of so-called user stories is based on two types of criteria: (i) what would be feasible, given the constraining costs and complexity for its technical development added up to the given local constraints (e.g. available infrastructure (no electricity, no internet), local purchasing power of people with very low incomes, and cultural issues such as language and (il-)literacy); (ii) what would be the most advantageous solution for the farmers. The proposed solutions/ideas are jointly evaluated and prioritized, resulting in a portfolio of user stories which are to be further elaborated. 
Case: Needs assessment with farmers in Mali. In 2015 our researchers and developers team started a collaboration with Malian farmer organization $\mathrm{AOPP}^{9}$, aimed at improving access to information and communication for smallholder farmers in Mali. AOPP is an umbrella organization of 240 smaller farmer organizations with a total of over 40,000 members across the whole country. AOPP's objective is to improve living conditions of farmers and food self-sufficiency through peasant agriculture, family farming, multi-functional, powerful scaling methods, within a strategic framework for poverty reduction.

In 2015 and 2016 a series of ICT4D needs assessment workshops was organized with AOPP in Bamako, Mali (Figures 3 and 4). The ICT developers team consisted of six people. The group of farmers consisted of fifteen participants from various regions of Mali: Mopti, Tombouctou, Gao, Segou, Sikasso, Bamako. Two potential service providers, an expert from a local NGO who works with rural community radios, and one local ICT expert from a small ICT enterprise were also present.

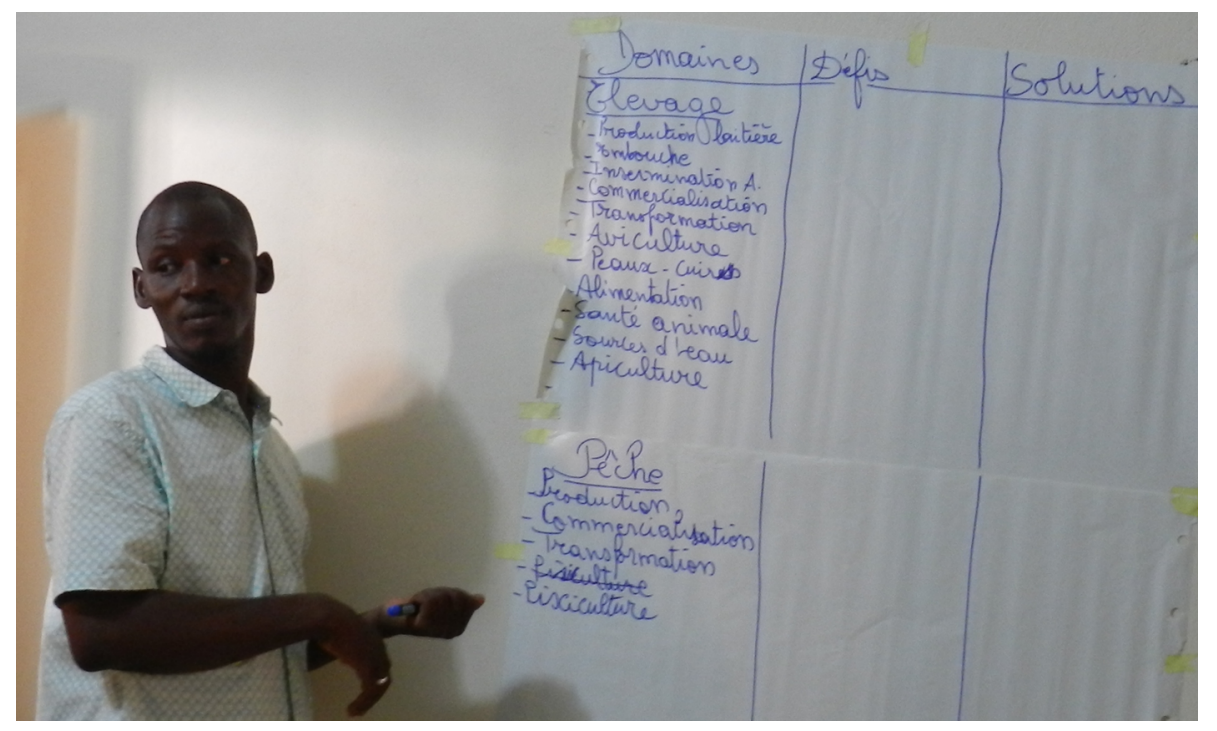

Figure 3. First assessment of domains, challenges and possible solutions done by farmers in Bamako, Mali, October 2015

The first, four-day, workshop took place at AOPP's office. Presentations, demos, plenary discussions, interviews and work in smaller subgroups were done. The first day was spent on mutual introductions and demonstrations of (voice-based) mobile systems in African languages. A demonstration was given of a local digital weather station, which can collect and diffuse information on local rainfall and other meteorological data. The farmers showed interest in receiving information on actual amount of rainfall per day, during the rainy season. This information, if available as a voice message in local language, on a daily basis, was considered useful for taking seeding and harvesting calendar decisions.

After demonstrations, three subgroups were formed and requested to make an inventory of local constraints in terms of access to information. This resulted in five domains: (i) agriculture, (ii) animal rearing, (iii) fishery, (iv) agro-forestry, and (v) internal organization of AOPP. The groups made a longlist of general constraints, which were presented next. During the group presentations, the moderator tried to elicit the problems and describe them in term of goals, stakeholders, relationships, and opportunities.

To encourage discussions related to the work of farmers, the third day of the workshop was spent in the field with the whole group. Existing workflows for which currently bottlenecks exist were

\footnotetext{
${ }^{9}$ AOPP is an acronym for Association des Organisations Professionnelles Paysannes.
} 
observed and analysed. Developers asked questions how things were currently organized and what could be improved.

An example is a user story about seeds. Seeds are important for farmers in Mali. They are produced and provided by a Malian institute of research in seeds, and are called 'semences de base'. Seed producing farmers obtain these basic seeds for the larger scale production of seeds. They produce what is referred to as "R1 seeds", which are certified seeds that can be sold at the market. To support the sales of local seeds, which is currently hampered by lack of communication channels (as farmers in the field are often illiterate and do not have computers or internet), a system should be available where farmers can offer seeds for sale or request for purchase.

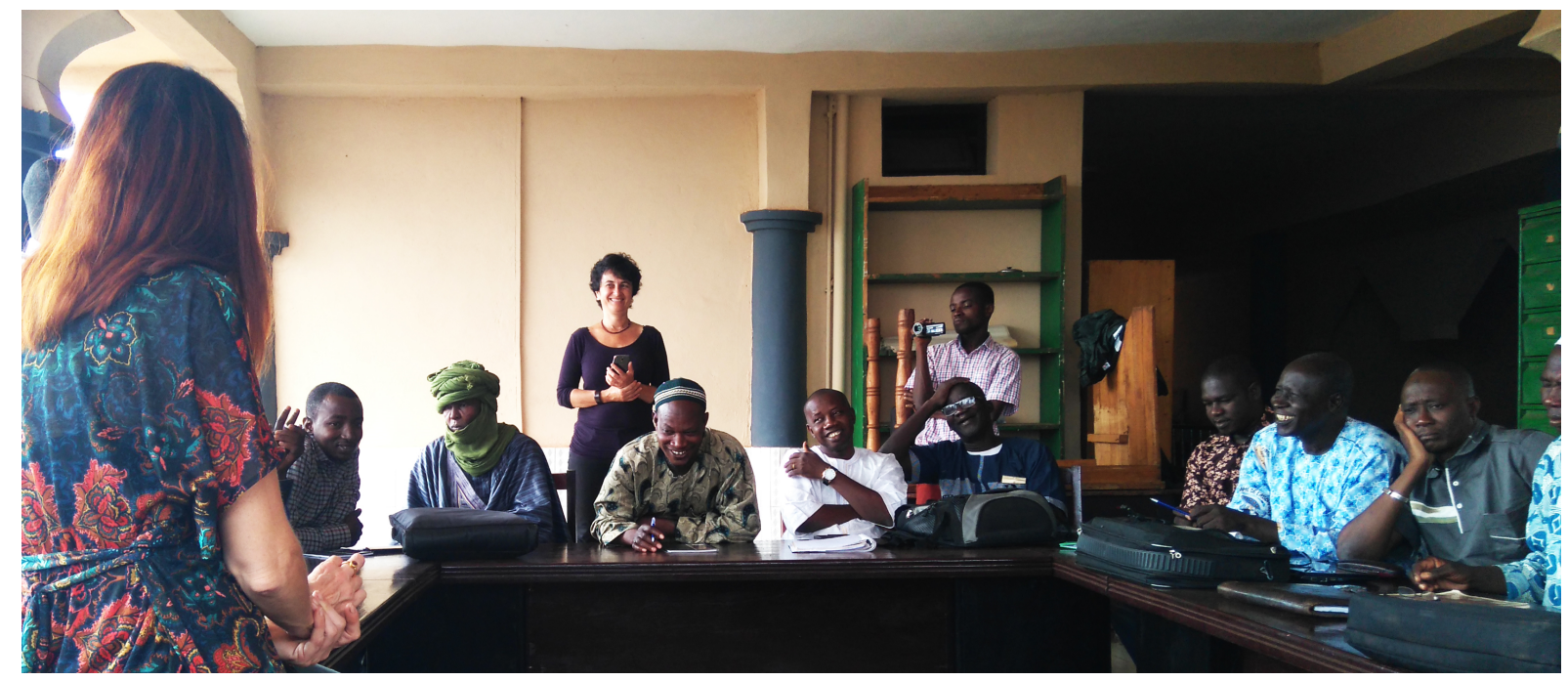

Figure 4. Assessment of information needs, by farmers during one of our workshops in Bamako, Mali, October 2015

The group sessions resulted in a wish list of three topics: (i) an application to facilitate information about the seeds market; (ii) an application to facilitate animal rearing; (iii) an application to facilitate information management of the AOPP organization itself; (iv) an application about rain and weather forecast ("Waati Kunafunni", which means weather information in the Bambara language; most applications are given meaningful names as proposed by attendees during our workshop sessions).

From the needs assessment a longlist of ideas was constructed that might be used for further elaboration. Promising user stories and business ideas, brought up by the participants, were collected on the article. The key idea was described briefly in a few sentences, including all stakeholders, their operational goals, and roles in the system.

The selection of the best user stories was done by the team of users and developers. A priority list was made as to what would be the most useful application(s) for the users. This was balanced against the technical feasibility, time and costs of development, and the possibility and costs to deploy it locally. The result was a shortlist of user stories that can be further elaborated and modeled.

\section{Use Case and Requirements Analysis - Structuring User Stories}

Having collected a portfolio of user stories and business ideas, the next step is elicitation of user requirements. This is a collaborative activity which can be done e.g. in interviews and focus group discussions, in which all available information is analysed. Rapid prototypes are built and demonstrated to users, if possible, even during the workshop.

To analyse, decompose, and structure all information that is collected during the workshops, we developed a systematic format-based method, which allows for modeling and specifying the 
architecture of the envisaged system, according to different sociotechnical perspectives. We apply a format which is understandable for the end users and also provides a specification baseline for technical development. To convey the key points, we use a mixed-method approach, with informal methods like short narratives, brief sketches, short films, cartoons and scenario scripts, combined with more formal methods such as UML (Unified Modeling Language) diagramming. This is then further elaborated to a detailed model specification of the system as needed for implementation of source code.

The proposed set-up is simple and compatible with guidelines, standards, and requirements for information systems development and information architectures. The importance is that the collected data from the workshops is elaborated as soon as possible into this format (when memory is still fresh). The advantage of this approach is to get a uniform description of the different ICT ideas, in which all information is elicited as much as possible. This has two purposes: to allow evaluation of the design and the requirements by key users; and to make technical specifications for the system's architecture. Below the use case modeling format we employ is presented and explained with an example case, namely, an idea for a voice-based micro-blogging system, which was proposed to help improve communication with farmers in Mali, cf. Figure 5.

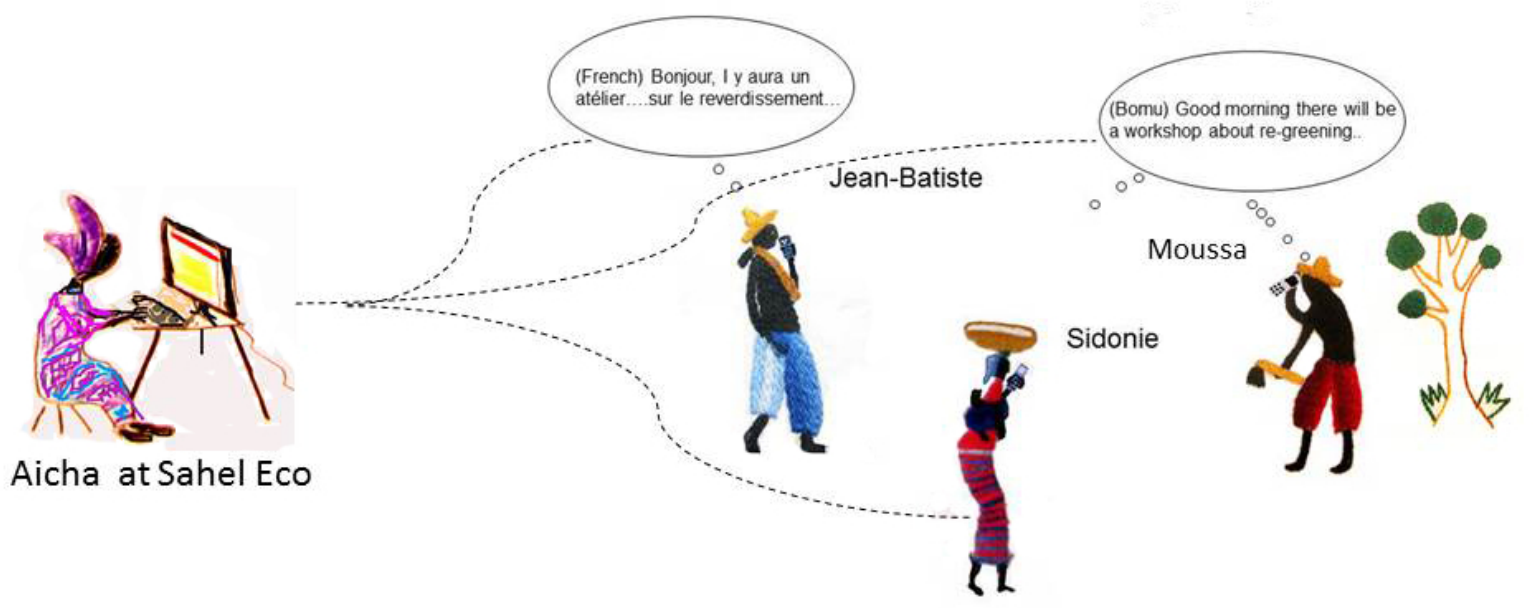

Figure 5. Informal sketch of an envisaged system, showing the scope of the system and its users

The case of a mobile event organizer. Sahel Eco is a small, Malian NGO with 11 employees who support rural communities e.g. with setting up local agro-value chains. Sahel Eco's staff are Malian experts in local farming. Most of them have been raised in a rural community themselves. One of them is Amadou Tangara in the village Tominian, Mali. Tangara did not have a background in ICT, but he became one of our key users and co-created and co-designed various ICT solutions with us. Amadou Tangara provided the following user story:

An extension worker often organizes workshops with rural communities in remote villages. The invitees are farmers who only have mobile phone, but do not use SMS. The farmers do not speak the same language: some speak French, others only Bambara or Bomu. To organize an event, the extension worker has to make at least twenty-five different phone calls, which consumes much time.

Can you build a system to send group voice messages to a number of users by mobile phone, in various languages? This idea is elaborated in the structured format below. To answer all questions, much information must be exchanged with the users, which helps the developers to better understand the problem in its context.

A structured format for use cases and requirements. Below, a structured format to model a user story is given, illustrated with case material from the mobile event organizer in Mali. We have 
consistently found in our research that such a relatively simple format - a combination of question checklists, structured narrative, visual diagrams, and overview conceptual models - works well in practice. Namely, key elements lend themselves well for explanation to and discussion with stakeholders and prospective users, while at the same time it provides an adequate baseline for further technical modelling and specification by ICT developers.

We consider the case of the event organizer: to build a system that sends automated phone messages to a group. The extension worker must enter a spoken message (in several languages), using a web-interface on his computer. Upon pressing the send-button, the system automatically calls a number of selected users on their mobile phones, each in his/her own language. A use-case scenario script or story board for this use case is presented in Figure 6.
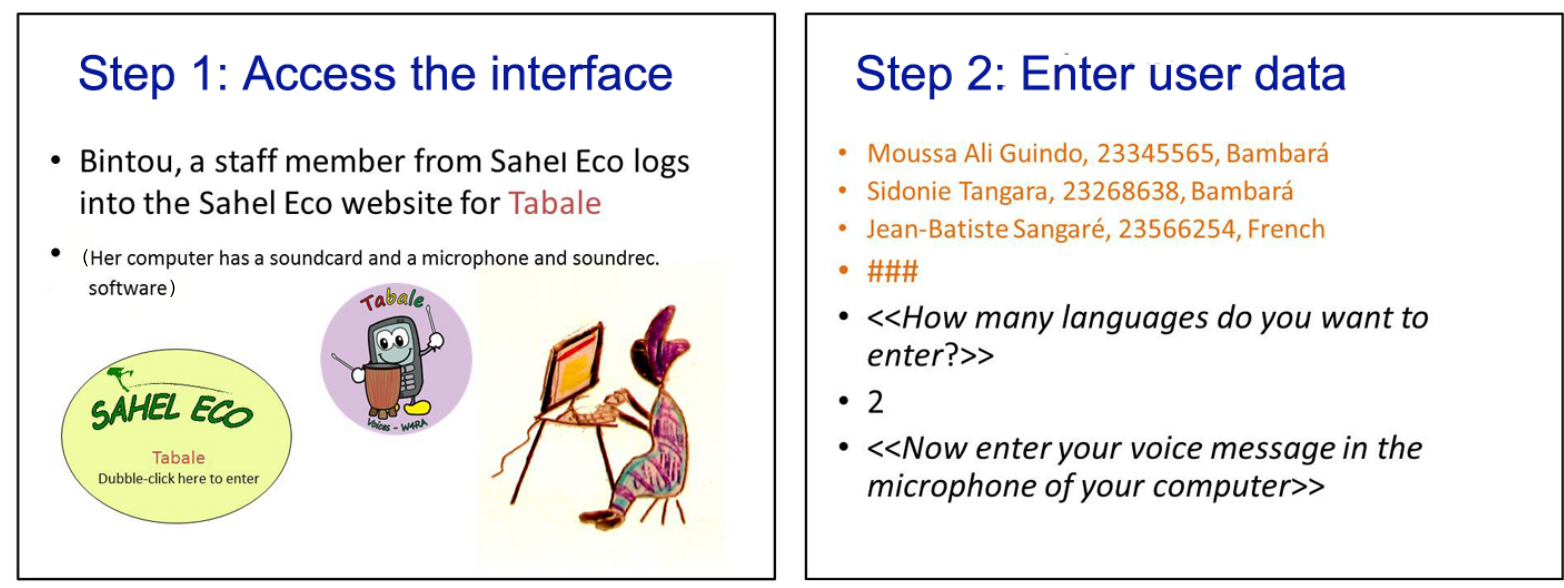

\section{Step 3: Enter spoken messages}

- "Bonjour, I y aura un atélier pour vous informer sur le reverdissement du Sahel, le mercredi, 20 juillet à 20 heures, dans le bureau de Sahel Eco, à Tominian." \#

- Enter the same message in the second language, press \# after you finish

- "Aw ni sogoma, gnongon là djè bina kè Tominian, sibiri don nèguè gnè tanidourou. aw bè wélé len don. aw ni thié."\#

Step 4: Users receive messages

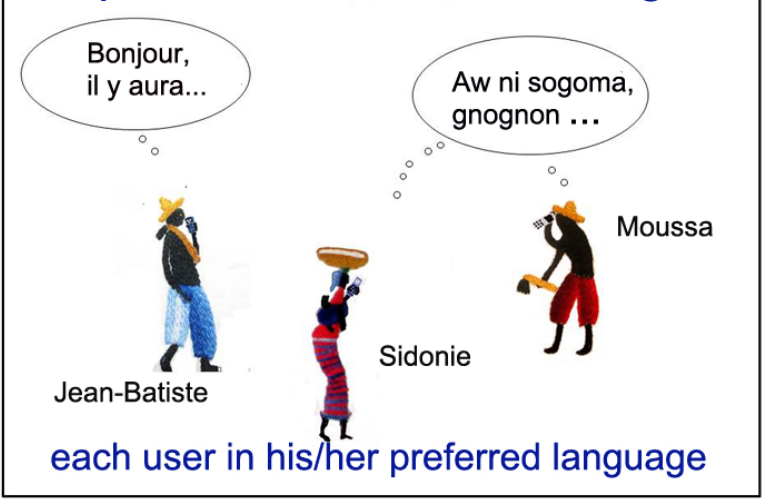

Figure 6. Storyboard showing a use case scenario for the envisaged Tabale system

Name. A characteristic, understandable, and distinctive label as unique identifier for each use case scenario. The name given by local users to this use case was Tabale, which in Bambara language is the village king's drum. When there is an emergency or an important event or meeting, the messenger goes from village to village by horse and beats the drum, to gather people from all the villages.

Summary of a key idea/short abstract. What is the key (business) idea and why is it valuable or of interest to consider? In the above case the idea is to organize events and workshops and gather rural communities to change ideas. The invitees are farmers who live in remote villages, and only have mobile phone, but do not use SMS. Moreover, the farmers speak different languages: some French, others local languages Bambara or Bomu. To organize an event, the NGO staff member has to make about fifty different phone calls, which takes too much time. 
Actors and goals. Who are the actors in the scenario and what are their roles/responsibilities and goals? The envisaged Tabale system has three actors, (i) an NGO webmaster, this is currently an employee from the local NGO; (ii) the farmer, who receives the message, gives a reaction (will attend meeting yes/no/does not know yet) and who can call back and retrieve the message at a later time; (iii) the person who provides technical support of the system. This information is summarized in Table 1.

Table 1. Stakeholders and their concerns for the Tabale use case

\begin{tabular}{|r|l|l|}
\hline ID & Actor & \multicolumn{1}{c|}{ Description } \\
\hline 1 & NGO & Manage users and user profiles (add new/update/delete users) \\
\hline 2 & NGO & Record audio in several languages (French, Bambara, Bomu) \\
\hline 3 & NGO & Create an event (add date, users, message) \\
\hline 4 & NGO & Manage events (add new, update, delete) \\
\hline 5 & NGO & Monitor incoming calls \\
\hline 6 & NGO & Launch event \\
\hline 7 & Farmer & Receive phone message communicating event \\
\hline 8 & Farmer & Respond pressing DTMF (Dual Tone - Multi Frequency) \\
\hline 9 & Farmer & Generate communiqué report \\
\hline 10 & Farmer & Call phone number to retrieve message \\
\hline 11 & Support & Monitor system; maintenance \\
\hline
\end{tabular}

Context and scope. Here, several questions are to be answered.

1. What is the layout or network configuration of the interactions between the parties involved in the scenario? The physical network for Tabale requires a system or platform that can generate and send voice messages to the phone network. This platform is displayed in Figure 7.

2. Who are the (external) stakeholders and what are their concerns? Apart from the users (the message sender and the receiving users) there must be service providers to deliver this service, including a local phone (GSM) network.

3. What is the scope of the scenario (especially, what is outside it, not considered, system boundary)? The scope for the case under consideration is shown in Figure 5.

4. What are success or performance measures for the scenario (especially in relation to what a pilot demonstration should be able to show)? The Tabale system is successful if the sender can issue a single message and multiple receivers can receive it by mobile phone, and are able to understand it, and reply to it.

5. What are important (pre)conditions that must be or are assumed to be satisfied for the scenario (context features, e.g. needed resources or infrastructure or other characteristics of the environment)? The system should work in the absence of an internet connection in the villages where the recipients live.

Use case scenario script. The central storyline (just like in a movie, video clip storyboard, animation, or demo; the script might e.g. be given in the form of a film or animation, showing the event-state chain of the actors' activities and interactions). The main scenario is given in a well-structured narrative. For our case study this is shown in Figure 6. 


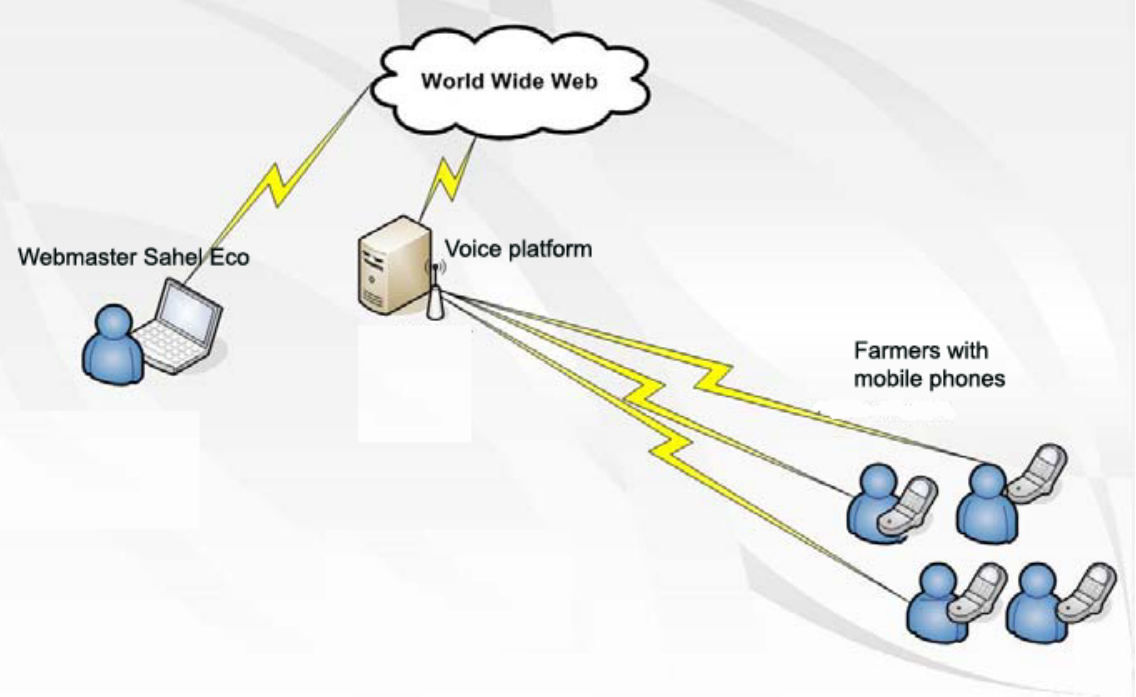

Figure 7. Network diagram of the Tabale system

Interaction and communication. Further information, e.g. in the form of a few UML sequence, state or activity diagrams. (This gives an insight into dynamics, interaction and control flows). Figure 8 gives a state diagram for the Tabale system, showing the different static states of the system. This model can be adjusted if needed.

Information concepts. Further information, e.g. in the form of a few UML class diagrams showing the meaning of important concepts. (This gives an insight into static data structures). Various UML diagrams were constructed for this use case. As an example, a state diagram is shown in Figure 8.

Technology infrastructure. What are the consequences for technologies and technology components (Internet/Web, mobile, information, communication, voice services, both hardware and software) that must be (made) available for the scenario to work? In our case the system should be able to connect a computer to the phone network and stream voice messages, and store incoming phone calls. The system should be able to work with an internet connection, but also without it.

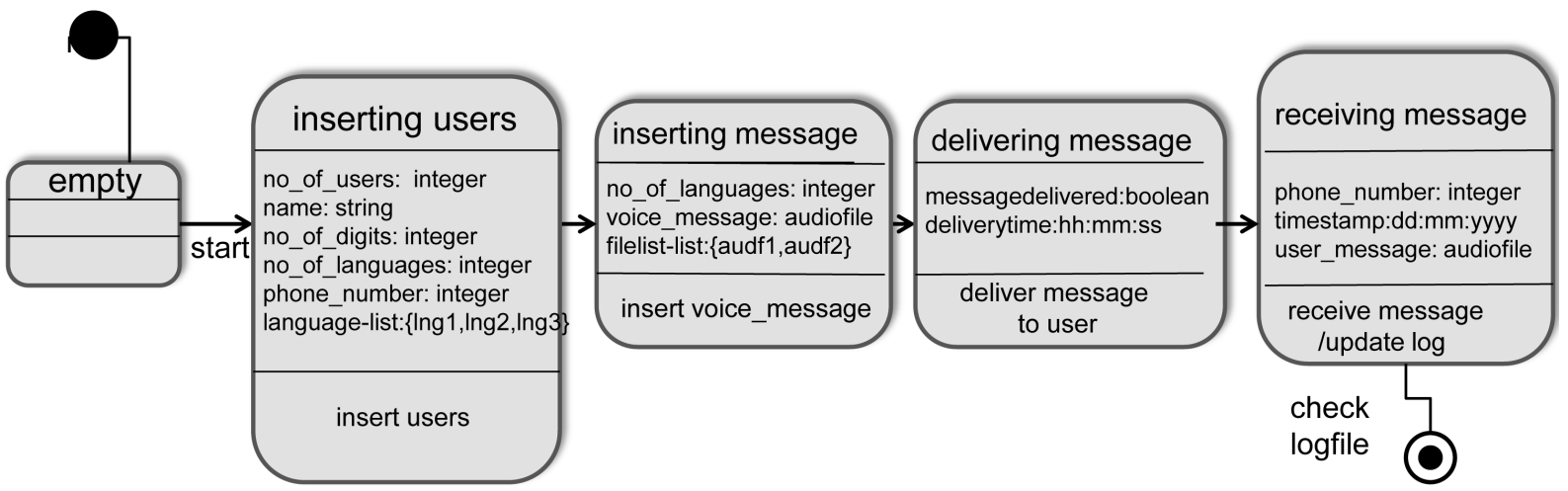

Figure 8. UML state diagram for Tabale 
Key requirements. So-called MoSCoW list of requirements [36] (Must have, Should have, Could have, Won't have) as a starting point for further architecture design, and system and component development. The following were essential (must have) requirements. For the mobile event organizer, Tabale, an essential (must have) requirement was a web interface where user profiles can be entered, including their phone numbers and language preferences; and that a voice message can be recorded in several languages; and sending the message to a number of phones at one button push. Should have requirement was the possibility for the user to reply and leave a message that is stored in the system and accessible via the web interface. It could have an option where users could easily phone in asynchronously. It will not have to rely on an internet connection to reach the users, since there is no internet in the villages. It will not use SMS to reach the users as they are often illiterate.

Cost considerations. What are estimated associated costs (operational, investment, development, in/outsource) for the envisaged technology infrastructure and components? Who carries these costs? The initial costs of the Tabale case are estimated as the costs of the platform and the initial installation. Recurrent costs are the maintenance of the system and phone costs for the NGO or extension worker. The initial development costs would be carried by the ICT4D project. The software would be made available as open source (free of licence cost). The operational costs would in this case be carried by the NGO as part of their exploitation.

Feasibility and sustainability. The following checklist of questions has to be answered:

1. What is the technical feasibility of the scenario (e.g. risk analysis, technical obstacles to overcome, system-level impacts)? Technically the Tabale system would be simple and robust. The problem is the phone connection which has to be local (to allow local phone calls).

2. What is the business and (socio-)economic feasibility and sustainability of the scenario? As a tool to communicate between an NGO and farmers, the feasibility and sustainability are well defined. The system saves time and is, therefore, useful and saves money.

3. What are possible goal conflicts and dependencies between the actors in the scenario? There are no serious goal conflicts identified for this case.

4. Are there preconditions for the scenario to work, and is it sufficiently interoperable with the wider context in a business as well as technical sense? The system runs on a platform that connects to a local phone network. This platform must, therefore, be available locally. The recipient users must have mobile phones.

\section{Develop, Test \& Deploy - Co-Creating the System in Cycles}

Development of ICT prototypes and demos is where possible done during the workshops, in the presence of users. Detailed work and implementation (coding) is done at distance, inbetween field visits. Software is constructed iteratively, to correct errors and refine and improve solutions during cycles of design, testing, redesign, testing, redesign, and deployment [37]. Users give information, provide feedback, and evaluate. The results of each cycle determine the actions of the next cycle. In contrast to deploying an end-user application at once, this ensures that solutions best fit the local goals and context.

Development is done in small Scrum ${ }^{10}$ teams. The style of working is agile, user-centered and non-hierarchical. It encourages creativity and personal commitment. There is close collaboration with a number of key users, who provide input and information for the system and evaluate the intermediate releases of the system, on the basis of evaluation protocols made.

\footnotetext{
${ }^{10}$ Scrum: https://www.scrumalliance.org/
} 
Field deployments of production-ripe prototypes give new information and often reveal additional requirements which were not known at the start. If possible, the system can be adjusted accordingly, for a second (sub-)release. To validate the results the system is evaluated various times.

Case: Testing Tabale, a voice-based system in Mali. The Tabale system prototype was built after the use-case description and subsequently tested in a real-life environment in Mali, by prospective end-users: two NGO staff members Amadou Tangara and Drissa Gana and five farmers from a small rural community near Tominian. The prototype was improved according to their feedback. Until November 2014 (when the telecom provider decided to discontinue the underlying voice platform), the system was successfully used by Sahel Eco to communicate with the farmers in the villages.

During the evaluation meeting a quick recapitulation was given by the workshop leader of the original legacy workflow - what people used to do before Tabale was deployed - and then the development team explained what the designed system was envisaged to do. The team tested the system, and evaluated its functionality according to a test protocol. The user interface was tested for different roles (normal user, administrator). All feedback from the users was collected. Not all users in the evaluation spoke French, so there was translation done between French and Bomu, the local language in this region.

In November 2012 two NGO staff members and five farmers in Tominian, Mali, tested Tabale, its voice-based interface, the use of the key-pad DTMF (press 1 for yes, 2 for no, etc.), the navigation of the voice menu and the quality of the pre-recorded voice messages. They gave feedback on several aspects of usability. Feedback was collected and Tabale was improved and released based on their comments.

As an example, one of the complaints from the users who evaluated the Tabale system was about the personal user profile. The first time a user logged into the system, a language selection was offered through a voice menu. This language was added to the user profile to avoid having to select the language each time he/she uses the system.

However, if the (unexperienced) user presses the wrong button the first time the system is used, s/he is stuck with a wrong language, which in addition cannot be changed anymore. This user feedback showed us how the initial design of the Tabale system had overlooked one realistic scenario of the Tabale use case. This 'bug' should be fixed in the next release, allowing users to reset their user profile whenever they want.

After the users' evaluation of the first cycle and having fixed bugs and added new functionality (if possible) based on new requirements, a new version was released. Follow-up questions pertained to local partners (users and business partners) the system about technical maintenance: "Is (more) training needed for users/providers?", "Is documentation clear and available?". Log files were assessed, face-to-face key-user interviews were done, to report on system usage and evaluations of user satisfaction. After implementation, the system was evaluated in a production environment by a panel of key users, looking at various aspects of the system. The Tabale system was used in a production environment for nearly two years, from beginning of 2013 to end of 2014.

\section{Sustainability Assessment - Understanding Value}

A farmer, say, in Tominian, Mali may be interested in a mobile voice-based messaging service that provides her with market information. However, she will only pay for the service when it creates real added value for her. A small entrepreneur such as a radio station, e.g. radio Moutian in Tominian, may be interested in participating in future commercial voice-service delivery. However, the radio station will only do so if the voice service can be provisioned in a profitable way, meaning that the revenues outweigh the expenses. 
In general, many ICT4D services involve a network of actors such as (small) companies and end users to produce and use the service at hand. We call such a network a networked value constellation [38], in which actors create, distribute, and consume objects of economic value with each other. In a networked value constellation, each participating actor should be able to create profit or increase of (socio)economic utility. If one or more actors fail to do so, in the long run the constellation cannot survive.

To design and evaluate a networked value constellation, we employ the $e^{3}$ value methodology [39]. This methodology graphically depicts networked value constellations, and is also capable to evaluate profitability for each actor involved. An example can be found in Figure 9. This diagram represents that a news provider (e.g. Al Jazeera, CNN, ORTM, BBC) pays for news items collected by local village reporters, which is aggregated by Foroba Blon, a service for hosting voice-enabled applications. In ICT4D projects, the $e^{3}$ value method comprises a number of steps:

- Concisely state the ICT4D idea. A textual description of the use case is made, but this time with the focus on the profit-and-loss responsible actors (e.g. companies, customers, etc.), and what they exchange of economic value with each other. Also, the customer needs, which can be satisfied by ICT services, are identified.

- Represent the ICT4D idea as an $\mathrm{e}^{3}$ value diagram. The textual representation of the ICT4D idea is the starting point for a more formal description using the $e^{3} v a l u e$ methodology. The first step in such a formalization is to draw the $e^{3}$ value diagram for the case at hand (see Figure 9 for an example). It is normal that the development of a high quality diagram takes several workshops with stakeholders and thus involves multiple iterations.

- Attribute numerical values to the constructs in the $\mathrm{e}^{3}$ value diagram. In order to allow for a quantitative sustainability assessment, $e^{3}$ value modeling constructs must be quantified themselves. Examples include the number of customers in a particular region and pricing schemes for the products and services in the model.

- Assess economic sustainability. The $e^{3}$ value software tool ${ }^{11}$ is capable of automatically generating net cash flow sheets for each actor in the $e^{3}$ value model. The net cash flow is calculated by standard methods as revenues minus expenses and each actor should have a positive value here. If not, the value model must be redesigned or the quantification must be done differently (e.g. higher prices). The assessment clearly shows which actors are the winners (in terms of earnings) and which actors have to pay for this.

- Perform sensitivity analysis. Obviously, sustainability assessment provides an estimate. The idea is that the $e^{3}$ value model is constructed before the ICT4D service is deployed. Therefore, e.g. the number of customers, prices to be paid, and more, are all estimated before the service is actually running. It may then be very well possible that the number of customers doubles, or in reality is substantially lower than estimated. For this reason, it is important to perform sensitivity analysis. During sensitivity analysis, important quantitative parameters of the $e^{3}$ value model are varied, which results in a better understanding of the model with respect to sensitivity of the net cash flow variables for each actor.

Case: The citizen journalism-based business model. We have developed a series of business models with local village reporters and local radio stations. These local village reporters collect news in their village and report the news to the local radio station they are related to. In turn, the local radio station makes news items out of these news reports, and broadcasts these.

One of the possible business models supposes that there are large news providers who look for local news items for their programs. Of course, these providers have their own reporters to cover the world-wide news, but also may want to present local news, also if they have no reporters physically available to report on local news from remote regions. Hence, a possible ICT4D business idea is

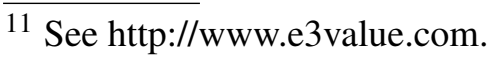


to use local stations to aggregate news items from local village reporters, such that these items can be used by large news providers, who also pay for these news items.

The corresponding $e^{3}$ value business model is shown in Figure 9. The $e^{3}$ value methodology supposes market segments, which are sets of profit-and-loss responsible actors, who are treated from a modeling perspective in the same way. Actors are enterprises or end-users, whose goal is to create a positive net cash flow (in the case of enterprises), or to increase economic utility (in the case of end-users). The news provider (consisting of e.g. Al Jazeera, ORTM, CNN, BBC) is an example of such a market segment. This provider needs news items (a need is depicted as a circle) for their programs, and wants to pay for these items. In $e^{3}$ value terminology: the news provider exchanges a news item (a value object) for money (also a value object), via its value interface (depicted as rounded rectangle). The value interface represents economic reciprocity: in order to obtain the news item, the news provider must pay (and also the other way around).

The Foroba Blon (FB, the name of the system) actor collects the news items from all local stations, and offers these (via its value interface) to the news providers. The FB actor and the news providers are connected via value transfers, representing the actual exchange of the news item for money. Moreover, FB needs a web hosting provider, since news items are made available via a web site. Web hosting is a non-trivial activity in Africa, especially from a cost perspective, and, therefore, should explicitly be part of the $e^{3}$ value model.

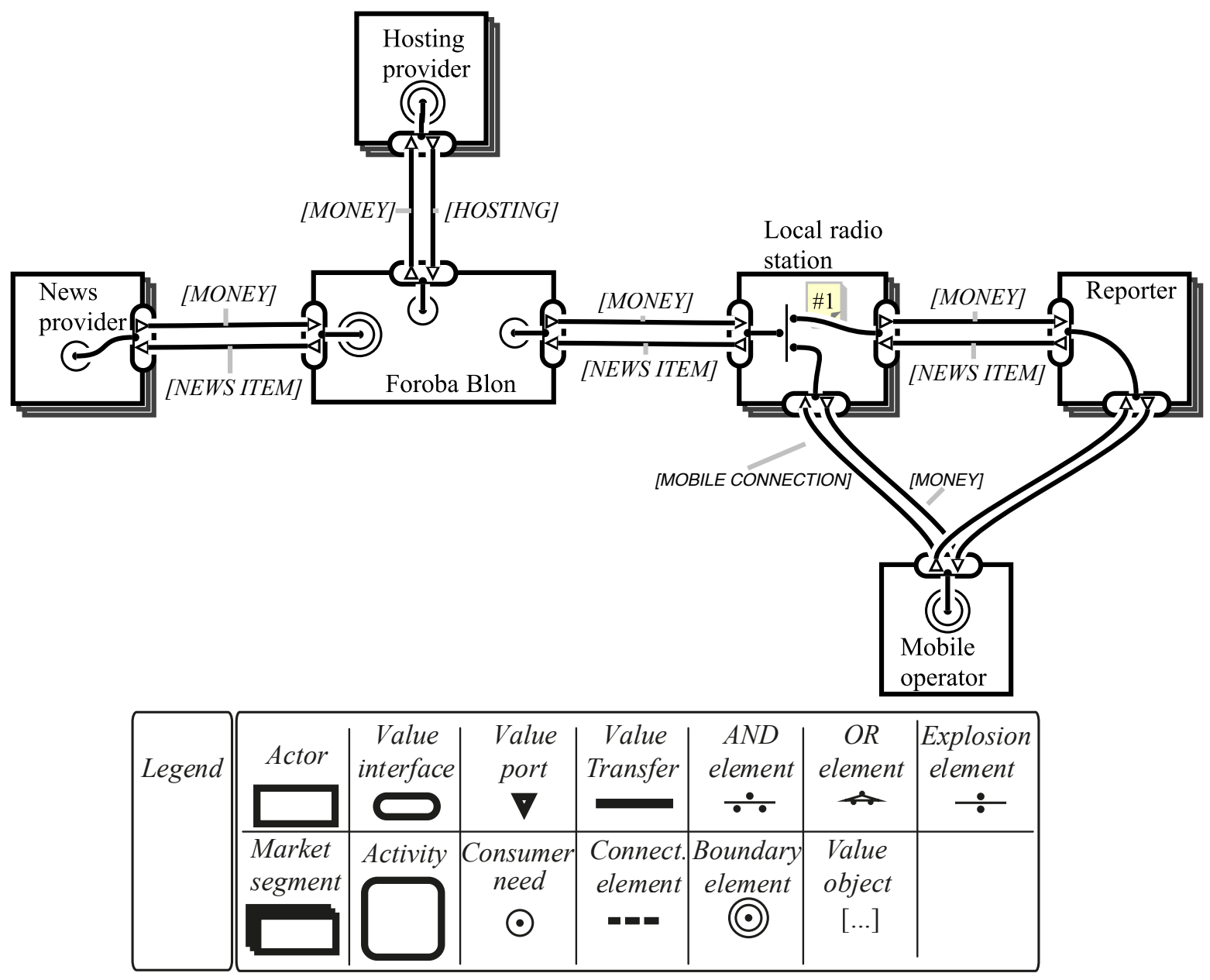

Figure 9. The news provider pays for obtaining regional news items

The FB actor needs to obtain news items of the local radio stations on a regular basis. For that purpose, the radio station must do two things: (1) buy the news items from village reporters, and pay them for each item, and (2) upload the news items to the FB actor. Since the radio station does 
not have direct internet access, the radio station needs a mobile phone connection (provided by the mobile operator) with the FB actor, to upload news items. The AND fork, annotated as 1, represents that in order to provide a news item to FB, the radio station needs to obtain the content from the village reporter, and needs a mobile telephone connection for the actual data transport.

Finally, local radio stations obtain news items from village reporters. In turn, these reporters are paid a fee per news item. The village reporters also need a mobile telephone connection to deliver the news to the radio stations.

In summary, modelling methodology such as outlined above can elucidate issues of economic sustainability in a systematic fashion. Often, several different business models and scenarios are conceivable, associated with different value network configurations of involved actors and stakeholders.

\section{Discussion and Conclusion}

This article has outlined a framework for developing ICT services in a low-resource development context. As discussed in Section 2, any such ICT4D framework should be able to address a set of important concerns that we summarized under the label low-resource context, and that are widely and commonly encountered in developing and emerging countries. Below we sketch how these concerns $(\mathrm{C} i)$ are addressed in our proposed ICT4D framework.

C 1 Local needs unknown. This is, we believe, the core issue for any real-world adequate ICT4D framework. Namely, the domain is rife with generic statements on the progress that ICT can (or even will) bring for development and, more specifically, for 'the poor', in alleviating or even eradicating poverty (see the opening sentences of this article, the United Nations Millennium Development and Sustainable Development Goals, Jeffrey Sacks' neoliberal Millennium Village Project [40], or much of the ICT4D policy literature (cf. [18] as a typical example)). Our point is that such statements have noble intentions, but are scientifically speaking no more than hypotheses about the possible importance of ICT, and so they have to be put at the test as any scientific hypothesis. This is however rarely done, or if so it is done from a big distance from the West as desk research. In our view, this is far from good enough. Therefore, our framework reserves a special place for needs assessment clarified through local field research that takes place on-the-ground and at the grass-roots level in a collaborative fashion akin to action research.

C 2 Context unknown. Information needs of people do not emerge and exist in isolation. Instead, they are situated within the specific contexts of people's everyday work, practice, life. The more this is different from the mainstream ICT developer context (certainly, if the latter is 'western' as it often is), the bigger the need to study it in detail. Hence, our framework includes extensive context analysis that is again in-the-field, on-the-ground at grassroots level. In other words, western academic desk research carried out at-a-distance as is often done in a development context is inadequate: again, it usually involves hypotheses that are scientifically untested in the Global South but are uncritically accepted by quite a many in the Global North.

C 3 Significant levels of low-literacy. This issue impacts heavily (also) on the technical ICT solutions that are entertained in the development, testing, and deployment component of our framework. The Internet, World Wide Web, and the use of social media, as well as the use of SMS in mobile phones, are heavily biased towards text, and so in fact discriminate against those who cannot read or write. Field research into this typically triggers the correction of such text biases and the prioritization of non-text solutions such as voice services.

C 4 Availability of crucial technology and infrastructure. Policy statements (and similarly, big-company attempts) make it often seem easy to resolve issues such as affordable internet for everyone everywhere. In contrast, the reality on-the-ground is that electricity is already a major issue that is not going away easily, especially in the rural areas where most of the 
poor live. So, any real ICT4D project has to shy away from (vaguely) stating what might be possible in a distant future, and is to start (realistically) from what is there already now. This again underlines the importance of empirical field research in ICT4D.

C 5 Low purchasing power of end users. This especially impacts the durability of ICT solutions beyond initial project development and piloting. Hence, in our framework it is factored into sustainability assessment, and in particular made explicit through the $e^{3}$ value methodology focused on the value network of stakeholders' balance of benefits and costs that we have introduced in this article.

C 6 Lacking understanding of ICT possibilities. This is a common problem also in the 'west' with non-ICT users. Our experience is that this problem can be quite well overcome within field research by properly designed demos and roadshows that are tailored to the specific interests of relevant local audiences. A key criterion is that technical demos and associated explanations are such that people can imagine for themselves how technological possibilities and affordances might work out in their own situation.

C 7 Mismatch between donor-sponsor goals and 'beneficiary' end users. This is a concern quite specific for ICT4D. In western projects it is typically the end-user company that ultimately pays the bill. This is also the assumption in the Agile approach to software engineering. In ICT4D this is, however, typically split: projects are structured according to donor and sponsoring funding agency ideas and goals about what are assumed to be the (supposed) beneficiaries' ("the poor") goals. Commonly, there is a big difference between the two and, minimally, such donor goals go untested against the reality in the supposed beneficiaries' context. Our framework provides an antidote to these biases by its emphasis on collaborative field research in all the ICT stages.

C 8 Sustainability concerns. It goes without saying that anyone would like an ICT development to be successful for many years, also after initial project development and piloting. We have introduced novel methods for sustainability assessment in this article. Often, in the conventional monitoring and evaluation (M\&E) approaches in development, this is studied after the fact, when it is, in fact, too late (not only post hoc but even post-mortem). Instead, we propose in our framework to perform sustainability assessments at an early stage, such that the associated what-if scenario analyses can impact ICT development at the early design stages.

Now, if we integrate the various components and aspects of our ICT4D framework (cf. Figure 1), and formulate the exposition and case examples in this article in a generalized fashion, we obtain an overview picture as in Figure 10. It gives a process model of our ICT4D service development framework in the form of an intention-strategy map [41], [42], a technique stemming from goal-oriented requirements engineering. Here, ovals denote intentions (goals), and arrows denote strategies to achieve these goals. In a single phrase, the framework for ICT4D service development is collaborative, adaptive, and iterative throughout.

Our framework as outlined above has emerged from a type of research that can be characterized as sociotechnical action research that is field-oriented. This has significant implications for how one approaches important scientific issues such as evaluation and generalization.

In line with the cyclic and iterative nature of action research (see e.g. [27]), development and evaluation are not strictly separated phases - including the typical monitoring and evaluation activities as demanded by donor agencies -, but are integrated in a continuous process of reflection and learning. Also the approach to generalization is different (cf. [28]): we employ what is known in (especially social science) research methodology literature as analytical generalization. This is a form of 'bottom-up' generalization based on looking for recurring patterns and salient abstractions that hold across an extensive set of individual cases characterized by contextually rich case study research materials. This is in clear contrast to the 'top-down' approach to generalization (where the starting point of thinking is not the individual case-in-context, but a population that is assumed to 
be contextless) typical of statistical quantitative studies. Accordingly, we have endeavoured in this article to provide a rich collection of examples and cases from our field materials so as to clarify the general points, abstractions, and claims made.

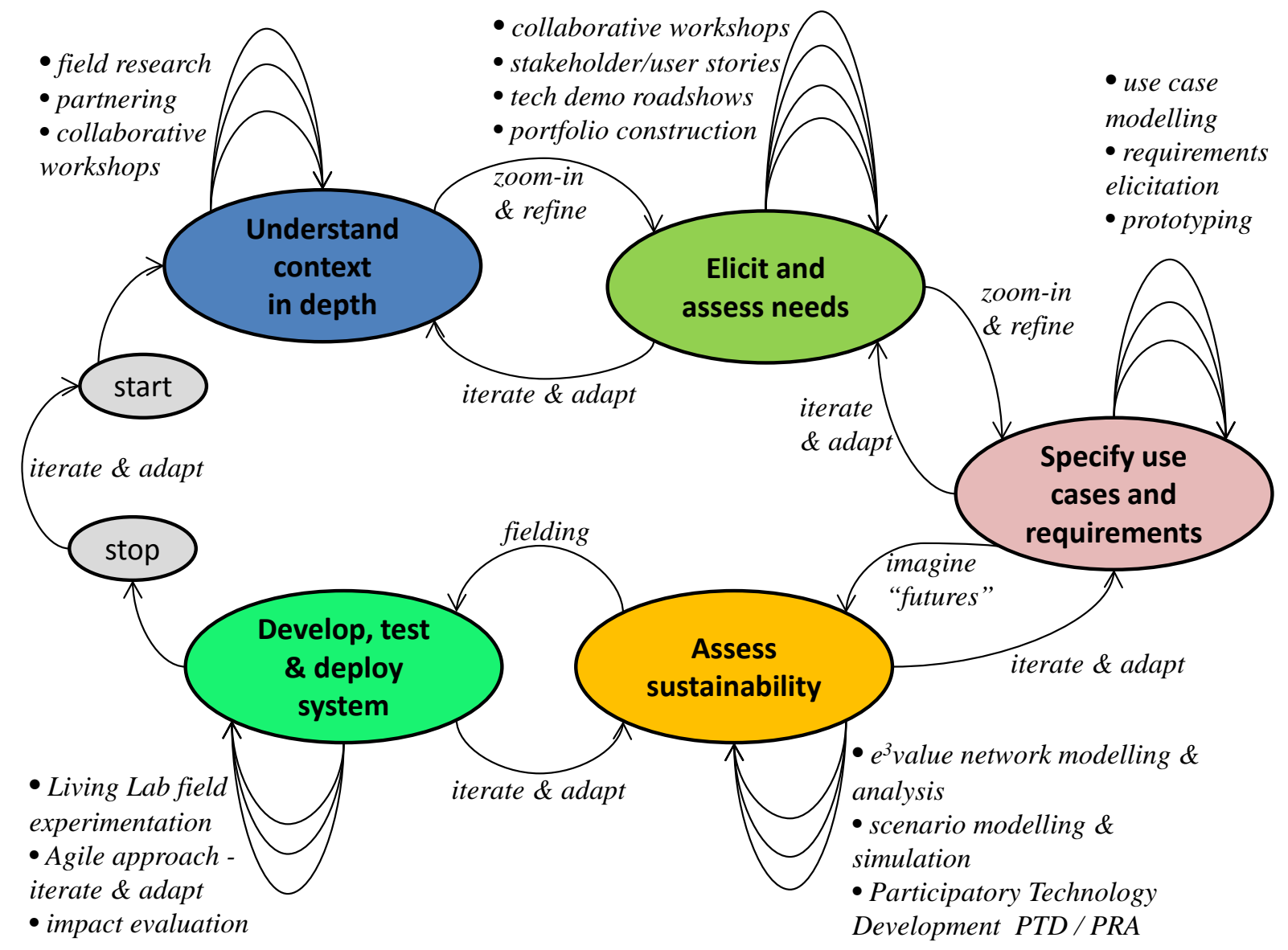

Figure 10. The collaborative-adaptive-iterative process model for our ICT4D Service Development framework, expressed in the form of an intention-strategy map

Some of the above-mentioned concerns and the ways our framework addresses them might seem pretty obvious and straightforward. Indeed, some of the mentioned concerns are also an issue in the 'western' Global North (such as the gap between ICT developers and non-ICT end users), and many suggested methods are already in existence (although the sustainability assessment methods we propose are novel). Within the ICT4D literature, there is a (limited) number of authors pointing in similar directions as we do, often from a human-computer interaction (HCI) perspective [21], [23], [25], [43], [44], [45].

Notwithstanding this, the present authors believe that ICT4D is not just ICT business-as-usual, because of the following reasons:

1. There is no denying that the concerns to be resolved in ICT developments are much more severe, critical and constraining in the case of ICT4D, and this on a very broad front, social as well as technical. What initially are matters of degree at some point combining turn into fundamental qualitative differences.

2. Perhaps surprisingly, many modern developments in software engineering, computer science, and information-systems practices, that are by now taken for granted by scientists and professional specialists, still escape the attention of the development circles that fund and drive (also) ICT projects.

3. More fundamentally, our observation is that a lot of external (mostly western) biases are commonly introduced into ICT4D projects. Many of these biases originate from uncritically 
adopted assumptions, by upfront presuming many things about stakeholder goals, needs, technologies, and their context. The basic problem here is that often these presumptions are not critically tested against developing countries' realities on the ground, in order to see whether they are actually warranted.

We will illustrate this with a few examples. Typical for development funding agencies and policies is a rather flat-world view on the introduction of new technologies and other measures and actions regarding development, as Ramalingam [46] explains in his informative book-length fulmination against the mainstream linear thinking of development agencies. Technology and associated innovation is positioned as an "intervention" that is externally introduced and subsequently triggers change for the poor, very much analogous to a medicine administered to an ill patient. In such an interventionist world view there is no place for the adaptive, iterative, or nonlinear (as Ramalingam phrases it) features of technological innovation and diffusion, in contrast to state-of-the-art knowledge [47].

This linear approach does not only affect projects in their design and development stages, but also carries over to evaluation research of project outcomes and impacts. It is common to find evaluation studies in a simplistic pretest-posttest format (the pretest is in development usually called a baseline study). In fact, the idea is highly similar to the decades-old positivist psychology (quasi-)experiment approach, and the more so if a quantitative (i.e. statistical) methods bias is involved. Contextual and processual aspects are thus naturally disregarded, as it were almost by necessity due to the research design. Translated into software engineering terms, in development funding agency circles the waterfall model still reigns supreme - although not by name: the equivalent project management term is logical framework or logframe [48].

As another example, we take an essay [18] that considers how modern ICTs might benefit the poor, in promoting a new phase of ICT in development dubbed ICT4D 2.0. On the concern of low-literacy it writes (p. 28): "Equating the poor in developing countries with illiteracy is a common mistake. Adult literacy, even in the world's poorest countries, is still greater than 50 percent, and two-thirds of 15- to 24-year olds are literate. Effectively, every community will have at least some literate members who can act as infomediaries (...)."

This is a clear case of uncritical interpretation and (mis)use of a simple statistic [49]. Moreover, such general statements as quoted above do carry practical implications, in this case, by suggesting that illiteracy is not an issue (anymore) for ICT4D development projects that supposedly are to the benefit of the poor. This is highly misleading. It is common and perhaps unavoidable that ICT4D desk research at-a-distance relies for its argument on simple statistics such as a global average. But it does introduce significant external biases that should not go unchecked. A simple statistical average argument overlooks a lot of on-the-ground key facts that basically relate to the underlying distributions. Here, e.g. (i) there is a big difference in literacy between urban and rural areas, and most of the poor in Africa live in rural agricultural regions; (ii) it ignores important gendered differences and issues as there is a clear literacy difference between men and women. In addition, the suggestion that the few literates in rural communities and villages will act as infomediaries contains a lot of unchecked wishful thinking, and ignores the many subtleties, known from practical experience as well as the scholarly literature, concerning the social networks that are involved in spreading sociotechnical innovations [47], [50].

Heeks's [18] assertion as a generalized statement is, therefore, fully unjustified. The root of the mistake lies in ignoring the strongly contextual aspects of ICT4D development projects ${ }^{12}$. The way to find out whether such statements and claims are actually warranted and have a grounding in reality is to investigate them in the field, as implied by our framework (Figure 10).

Summing up, the distinctive central characteristics of our ICT4D service development framework are, first, that it is thoroughly and inherently collaborative, adaptive, and iterative.

12 This furnishes one reason why the present authors believe it is time to consider ICT4D 3.0 [51]. 
Second, this is the case throughout the whole development lifecycle. Third, it puts even more emphasis on the importance of the early upstream stages of ICT systems development, especially on analyzing needs in the context - even without ICT technologies necessarily already being implied - and on doing so through forms of sociotechnical field action research carried out 'dans le terrain' (in the field). The reason is that inherently sociotechnical systems such as ICT4D services have a heavily contextualized nature. This is a 'known unknown' that requires significant amounts of tedious research. But attempting to fill the knowledge gap by making general assumptions at-a-distance is a recipe for failure.

Acknowledgements. The research for this article is part of the W4RA programme, the Web Alliance for Regreening in Africa ${ }^{13}$. The authors thank Victor de Boer, Chris van Aart, Wendelien Tuyp, Amadou Tangara, Adama Tessougué, Nana Baah Gyan, Francis Dittoh, Stéphane Boyera, Mary Allen, Max Froumentin, Aman Grewal, Chris Reij, Mathieu Ouedraogo, Réseau MARP, Prof. Saa Dittoh, UDS, AOPP, SBC4D and 2CoolMonkeys BV for their great contributions to the research and development projects described in this article.

\section{References}

[1] P.T.H. Unwin, Ed., "ICT4D: Information and Communication Technology for Development," Ser. Cambridge Learning, 1st edition, Cambridge University Press, pp. 404, 2009.

[2] B.S. Gigler, "Development as Freedom in a Digital Age: Experiences From the Rural Poor in Bolivia," World Bank Publications, 2015. [Online]. Available: https://doi.org/10.1596/978-1-4648-0420-5

[3] D. Kleine, "Technologies of Choice? ICTs, Development, and the Capabilities Approach," Cambridge, MA, USA, the MIT Press, pp. 264, 2013. [Online]. Available: https://doi.org/10.3386/w17129

[4] I. Mbiti and D.N. Weil, "Mobile Banking: The Impact of M-Pesa in Kenya," National Bureau of Economic Research, Tech. Rep., 2011.

[5] I.E. Group, "Capturing Technology for Development. An Evaluation of World Bank Group Activities in Information and Communication Technologies," vol. 1, 2011.

[6] R. Heeks, "Information Systems and Developing Countries: Failure, Success, and Local Improvisations," The Information Society, Board Report, vol. 18, no. 2, pp. 101-112, 2002. [Online]. Available: http://doi.org/10.1080/19452829.2013.875736

[7] M. Ali and S. Bailur, "The Challenge of 'Sustainability' in ICT4D - Is Bricolage the Answer?" in Proceedings of the 9th International Conference on Social Implications of Computers in Developing Countries, 2007.

[8] M. Marais, "Analysis of the Factors Affecting the Sustainability of ICT4D Initiatives," 2011.

[9] S. Buhigiro, "The Role if Telecentres in Promoting Socio-Economic Development in Rwanda." Ph.D. dissertation, 2013. [Online]. Available: https://core.ac.uk/download/pdf/39671238.pdf

[10] R. Ariyabandu, "Role of Telecentres as Knowledge Networks: Successes and Challenges," pp. 1-150, 2009. [Online]. Available: http://telecentres.mfep.gov.dz/fileadmin/user_upload/bibilio_files/Role_of_ telecentre.pdf

[11] B.L. Samuelson and S.W. Freedman, "Language Policy, Multilingual Education, and Power in Rwanda," Language Policy, vol. 9, no. 3, pp. 191-215, 2010. [Online]. Available: https://doi.org/10.1007/s10993-010-9170-7

\footnotetext{
${ }^{13}$ Web alliance for Regreening in Africa, http://w4ra.org.
} 
[12] M. De Bruijn, F.B. Nyamnjoh and I. Brinkman, Eds., "Mobile Phones: The New Talking Drums of Everyday Africa," Cameroon: Langaa RPCIG, African Books Collective, pp. 184, 2009.

[13] M. Gakuru, K. Winters and F. Stepman, "An Inventory of Innovative Farmer Advisory Services Using ICTs," in Forum for Agricultural Research in Africa, Report, 2009.

[14] S. Gumbo, H. Thinyane, M. Thinyane, A. Terzoli and S. Hansen, "Living Lab Methodology as an Approach to Innovation in ICT4D: The Siyakhula Living Lab Experience," in Proceedings of the IST-Africa 2012 Conference, vol. 24, pp. 29-74, 2012.

[15] Y. Anokwa, N. Ribeka, T. Parikh, G. Borriello and M.C. Were, "Design of a Phone-Based Clinical Decision Support System for Resource-Limited Settings," in Proceedings of the Fifth International Conference on Information and Communication Technologies and Development, ACM, pp. 13-24, 2012. [Online]. Available: https://doi.org/10.1145/2160673.2160676

[16] C. Hartung, A. Lerer, Y. Anokwa, C. Tseng, W. Brunette and G. Borriello, "Open Data Kit: Tools to Build Information Services for Developing Regions," in Proceedings of the 4th ACM/IEEE International Conference on Information and Communication Technologies and Development, ACM, pp. 18, 2010. [Online]. Available: https://doi.org/10.1145/2369220.2369236

[17] N.B. Gyan, V. de Boer, A. Bon, C. van Aart, H. Akkermans, S. Boyera, M. Froumentin, A. Grewal and M. Allen, "Voice-Based Web Access in Rural Africa," in Proceedings of the 5th Annual ACM Web Science Conference, ACM, pp. 122-131, 2013. [Online]. Available: https://doi.org/10.1145/2464464.2464496

[18] R. Heeks, "ICT4D 2.0: The Next Phase of Applying ICT for International Development," Computer, vol. 41, no. 6, pp. 26-33, 2008. [Online]. Available: https://doi.org/10.1109/mc.2008.192

[19] R. Heeks and A. Molla, "Compendium on Impact Assessment of Ict-For-Development projects," Tech. Rep., 2009.

[20] R. Gomez and S. Pather, "ICT Evaluation: Are We Asking the Right Questions?" The Electronic Journal of Information Systems in Developing Countries, vol. 50, 2011.

[21] K. Toyama, "Human-Computer Interaction and Global Development," Foundations and Trends in Human-Computer Interaction, vol. 4, no. 1, pp. 1-79, 2010. [Online]. Available: https://doi.org/10.1561/1100000021

[22] M.R. Ho, T.N. Smyth, M. Kam and A. Dearden, "Human-Computer Interaction for Development: The Past, Present, and Future," Information Technologies \& International Development, vol. 5, no. 4, pp. 1-18, 2009.

[23] K. Pitula, D. Dysart-Gale and T. Radhakrishnan, "Expanding Theories of HCI: A Case Study in Requirements Engineering for ICT4D," Information Technologies \& International Development, vol. 6, no. 1, pp. 78-93, 2010.

[24] T.S. Parikh and E.D. Lazowska, "Designing an Architecture for Delivering Mobile Information Services to the Rural Developing World," in Proceedings of the 15th international conference on World Wide Web. ACM, pp. 791-800, 2006. [Online]. Available: https://doi.org/10.1145/1135777.1135897

[25] A. Dearden and H. Rizvi, "Adapting Participatory and Agile Software Methods to Participatory Rural Development," in Proceedings of the Tenth Anniversary Conference on Participatory Design 2008, Indiana University, pp. 221-225, 2008.

[26] R. Gomez, L.F. Baron and B. Fiore-Silfvast, "The Changing Field of ICTD: Content Analysis of Research Published in Selected Journals and Conferences, 2000-2010," in Proceedings of the Fifth International Conference on Information and Communication Technologies and Development, ACM, pp. 65-74, 2012. [Online]. Available: https://doi.org/10.1145/2160673.2160682 
[27] P. Checkland, "Systems Thinking, Systems Practice,” John Wiley \& Sons, 1999.

[28] C. Robson, "Real World Research: A Resource for Users of Social Research Methods in Applied Settings," Wiley Chichester, 2011.

[29] R.J. Wieringa, "Design Science Methodology for Information Systems and Software Engineering," Springer-Verlag Berlin Heidelberg, 2014. [Online]. Available: https://doi.org/10.1007/978-3-662-43839-8

[30] A. Bon, V. de Boer, N.B. Gyan, C. van Aart et al., "Use Case and Requirements Analysis in a Remote Rural Context in Mali," in Requirements Engineering: Foundation for Software Quality, in Proceedings of the 19th International Working Conference, REFSQ 2013, Essen, Germany, April 8-11, 2013, Springer, pp. 331-346, 2013. [Online]. Available: https://doi.org/10.1007/978-3-642-37422-7_24

[31] B. Bergvall-Kareborn and A. Stahlbrost, "Living Lab: An Open and Citizen-Centric Approach for Innovation," International Journal of Innovation and Regional Development, vol. 1, no. 4, pp. 356-370, 2009. [Online]. Available: https://doi.org/10.1504/ijird.2009.022727

[32] T. Dingsøyr, S. Nerur, V. Balijepally and N.B. Moe, "A Decade of Agile Methodologies: Towards Explaining Agile Software Development," Journal of Systems and Software, vol. 85, no. 6, pp. 1213-1221, 2012. [Online]. Available: https://doi.org/10.1016/j.jss.2012.02.033

[33] D. Leffingwell, "Agile Software Requirements: Lean Requirements Practices for Teams, Programs, and the Enterprise," Addison-Wesley Professional, 2010.

[34] E. Gottesdiener, "Requirements by Collaboration: Getting It Right the First Time," IEEE Software, vol. 20, no. 2, pp. 52-55, 2003. [Online]. Available: https://doi.org/10.1109/ms.2003.1184167

[35] P. Kotler, "Marketing Management: Analysis, Planning, Implementation and Control," Englewood Cliffs, NJ: Prentice Hall, 1988.

[36] H. Van Vliet, "Software Engineering: Principles and Practice," New York, NY: Wiley, 1993.

[37] D. Leffingwell and D. Widrig, "Managing Software Requirements: A Use Case Approach," Pearson Education, 2nd edition, pp. 544, 2003.

[38] R. Normann and R. Ramírez, "Designing Interactive Strategy - From Value Chain to Value Constellation," Chichester, UK: John Wiley \& Sons Inc., Long Range Planning, vol. 28, no. 5, 1994. [Online]. Available: https://doi.org/10.1016/0024-6301(95)90236-8

[39] J. Gordijn and H. Akkermans, "Value Based Requirements Engineering: Exploring Innovative E-Commerce Ideas," Requirements Engineering Journal, vol. 8, no. 2, pp. 114-134, 2003. [Online]. Available: https://doi.org/10.1007/s00766-003-0169-x

[40] J.D. Sachs and J.W. McArthur, "The Millennium Project: A Plan for Meeting the Millennium Development Goals,” The Lancet, vol. 365, no. 9456, pp. 347-353, 2005.

[41] J. Ralyté, N.A. Maiden, C. Rolland and R. Deneckère, "Map-Driven Modular Method Re-Engineering: Improving the Rescue Requirements Process," in CAiSE Short Paper Proceedings, CEUR, pp. 157-162, 2005.

[42] C. Rolland, "Capturing System Intentionality With Maps," in Conceptual Modelling in Information Systems Engineering, Springer, pp. 141-158, 2007. [Online]. Available: https://doi.org/10.1007/978-3-540-72677-7_9

[43] E.H. Blake and W.D. Tucker, "Socially Aware Software Engineering for the Developing World," 2006. [Online]. Available: https://repository.uwc.ac.za/bitstream/handle/10566/662/BlakeTucker-IST2006. pdf?sequence $=1 \&$ is Allowed=y 
[44] A. Dearden, H. Rizvi, R. DePaula, C. Oyugi and H. Winschiers-Theophilus, "Participatory Design and International Development," in Proceedings of the Tenth Anniversary Conference on Participatory Design 2008, Indiana University, pp. 293-294, 2008.

[45] K. Pitula and T. Radhakrishnan, "On Eliciting Requirements From End-Users in the ICT4D Domain," Requirements Engineering," vol. 16, no. 4, pp. 323-351, 2011. [Online]. Available: https://doi.org/10.1007/s00766-011-0127-y

[46] B. Ramalingam, “Aid on the Edge of Chaos,” Oxford University Press, 2013.

[47] E. Rogers, "Diffusion of Innovations,” New York: Free Press, 5th edition, pp. 576, 2003.

[48] L. Rosenberg and L. Posner, "The Logical Framework: A Manager's Guide to a Scientific Approach to Design and Evaluation," Practical Concepts Incorporated, Washington, DC, 1979.

[49] D. Huff, "How to Lie With Statistics," New York, NY: Norton, 1954.

[50] M. Mudhara, C. William, S. Di Prima, S. Dittoh and M. Sessay, Eds., "Community Innovations in Sustainable Land Management," Earthscan Studies in Natural Resource Management, Routledge, pp. 245, 2016.

[51] A. Bon and H. Akkermans, "Rethinking Technology, ICTs and Development: Why It Is Time to Consider ICT4D 3.0," Tech. Rep., 2015. [Online]. Available: http://w4ra.org/wp-content/uploads/ 2015/01/ICT4D3.pdf 